Research Article

\title{
Efficiency Improvement of a Capacitive Deionization (CDI) System by Modifying 3D SWCNT/RVC Electrodes Using Microwave-Irradiated Graphene Oxide (mwGO) for Effective Desalination
}

\author{
Ali Aldalbahi $\mathbb{D}^{1},{ }^{1}$ Mostafizur Rahaman ${ }^{D},{ }^{1}$ Mohammed Almoiqli, ${ }^{2}$ Al Yahya Meriey, ${ }^{1}$ \\ and Govindasami Periyasami ${ }^{1}$ \\ ${ }^{1}$ Department of Chemistry, College of Science, King Saud University, Riyadh 11541, Saudi Arabia \\ ${ }^{2}$ Nuclear Sciences Research Institute, King Abdulaziz City for Science and Technology, Riyadh 11442, Saudi Arabia \\ Correspondence should be addressed to Ali Aldalbahi; aaldalbahi@ksu.edu.sa
}

Received 21 March 2020; Revised 27 June 2020; Accepted 21 August 2020; Published 7 September 2020

Academic Editor: David Cornu

Copyright ( 2020 Ali Aldalbahi et al. This is an open access article distributed under the Creative Commons Attribution License, which permits unrestricted use, distribution, and reproduction in any medium, provided the original work is properly cited.

\begin{abstract}
This work is aimed at improving the electrosorption capacity of carbon nanotube/reticulated vitreous carbon- (CNT/RVC-) based $3 \mathrm{D}$ electrodes and decreasing the duration of electrosorption-desorption cycles by facilitating the ions' adsorption and desorption on the electrode surface. This was achieved by preparing composites of microwave-irradiated graphene oxide (mwGO) with CNT. All composite materials were coated on RVC by the dip-coating method. The highest loading level was $50 \mathrm{mg}$. This is because it exhibited the maximum electrosorption capacity when tested in terms of geometric volume. The results showed that the 9CNT/mwGO/RVC electrode exhibited $100 \%$ capacitive deionization (CDI) cyclic stability within its $1^{\text {st }}$ five cycles. Moreover, $27.78 \%$ time was saved for one adsorption-desorption cycle using this electrode compared to the CNT/RVC electrode. In addition, the ion removal capacity of $\mathrm{NaCl}$ by the $9-\mathrm{CNT} / \mathrm{mwGO} / \mathrm{RVC}$ electrode with respect to the mass of the electrode $(3.82 \mathrm{mg} / \mathrm{g})$ has increased by $18.27 \%$ compared to the CNT/RVC electrode $(3.23 \mathrm{mg} / \mathrm{g})$ when measured at the optimum conditions. In a complete desalination process, the water production per day for the 9-CNT/mwGO/RVC electrode was increased by $67.78 \%$ compared to the CNT/RVC electrode when measured within the same CDI cell using $\mathrm{NaCl}$ solution of concentration less than $1 \mathrm{mg} / \mathrm{L}$. When considered volume of $1 \mathrm{~m}^{3}$, this optimum $9-\mathrm{CNT} / \mathrm{mwGO} / \mathrm{RVC}$ electrode produces water $29,958 \mathrm{~L}$ per day. The highest electrosorption capacity, when measured experimentally at $500 \mathrm{mg} / \mathrm{L} \mathrm{NaCl}$ feed concentration, was $10.84 \mathrm{mg} / \mathrm{g}$ for this optimum electrode, whereas Langmuir isotherm gave the theoretically calculated highest value as $16.59 \mathrm{mg} / \mathrm{g}$. The results for the $9-\mathrm{CNT} / \mathrm{mwGO} / \mathrm{RVC}$ composite electrode demonstrate that it can be an important electrode material for desalination in CDI technology.
\end{abstract}

\section{Introduction}

The electrosorption capacity and stability of an electrode depend on its pore structure, surface area, and electrical conductivity of electrode [1-6]. These play a significant role in the improvement of electrical double-layer capacitance in a capacitive deionization (CDI) system. This could occur by a uniform distribution of macropores that provide better electrochemical accessibility and facilitates rapid and easy ion transport. Nowadays, carbon materials like carbon nanofiber (CNF), carbon nanotubes (CNTs), graphene, and reticulated vitreous carbon (RVC) are used as electrode materials in a CDI system [7-10]. Wang et al. have shown that the electrical conductivity of electrode materials plays a great role in the performance of a CDI system [6]. They prepared a monolithic composite electrode using reduced graphene oxide (rGO) and activated carbon nanofiber (aCNF) through an ultrasound-assisted electrospinning technique. The 
electrosorption capacity of desalination was recorded for the $\mathrm{NaCl}$ solution as $9.2 \mathrm{mg} / \mathrm{g}$, which was governed by the formation of an electrical double layer and can be further improved by increasing the electrical conductivity of the electrode.

CNTs were accidentally discovered in 1991 by a Japanese scientist, Iijima, using an arc-discharge process [11]. Individual CNT can be either conducting or semiconducting, depending on the CNT structure [12]. Several physical properties of CNTs are of particular importance for the CDI application that is electrical conductivity, thermal conductivity, surface area, and mechanical strength. CNTs are one of the strongest materials in the world with elastic modulus reaching to 1 terapascal $(\mathrm{TPa})$ and strength between 50 and 100 gigapascal $(\mathrm{GPa})[13]$. These extraordinary mechanical properties make them theoretically at least 100 times stronger and 5 times lighter than an equivalent weight of the strongest steel. CNTs have also demonstrated high thermal conductivity compared to other high thermally conductive materials such as copper [14]. Kwon and Kim predicted that the thermal conductivity can reach up to $6600 \mathrm{~W} / \mathrm{mK}$ [15]. CNT shells can be either metallic or semiconducting in nature, depending on their chirality and their conformation. The CNTs could replace copper wire for electricity transport because its electrical conductivity is higher than copper [16]. The above characteristics make CNTs an ideal case for real-world applications including electrical field emission, conductive and mechanically reinforced plastics, energy storage, field-effect transistors, flexible transparent electrodes, solar cells, medical applications, water desalination, and capacitive deionization [12, 17-27]. The application of CNT membranes has impacted in the area of water technology development with their ultrahigh water flux and low biofouling potential.

Graphene has recently been attracted huge attention among the scientific communities because of its unique characteristics like large theoretical specific surface area $\left(2630 \mathrm{~m}^{2} / \mathrm{g}\right)$, high intrinsic mobility $\left(200,000 \mathrm{~cm}^{2} / \mathrm{vs}\right)[28$, 29], high tensile modulus (1 TPa) [30], good thermal conductivity $(\sim 5000 \mathrm{~W} / \mathrm{mK})$ [31], high optical transmittance $(97.7 \%)$, and high electrical conductivity [32, 33]. Various applications of graphene have been reported such as a catalytic electrode in fuel cell [34], transparent electrode in solar cell [35], supercapacitors [36], electrode in sensors [37], and transistors [38].

The most common approach to graphite exfoliation is the use of strong oxidizing agents to produce graphene oxide. The first production of graphene oxide was demonstrated by Oxford chemist Brodie in 1859, who added a portion of potassium chlorate $\left(\mathrm{KClO}_{3}\right)$ to a slurry of graphite in fuming nitric acid $\left(\mathrm{HNO}_{3}\right)$ [39]. Later in 1898, Staudenmaier improved Brodie's technique by using concentrated sulphuric acid $\left(\mathrm{H}_{2} \mathrm{SO}_{4}\right)$ as well as fuming nitric acid and adding the potassium chlorate solution after certain intervals of time during the course of reaction [40]. This small change in the procedure made the production of highly oxidized GO within roughly a week. In the 1950s, Hummers and Offeman reported a method, which is most commonly used today with its minor modification for GO production that could be done within roughly $2 \mathrm{~h}$ and at lower temperatures [41]. In this approach, the graphite is oxidized by treating with a mixture of potassium permanganate $\left(\mathrm{KMnO}_{4}\right)$ and sodium nitrate $\left(\mathrm{NaNO}_{3}\right)$ in concentrated $\mathrm{H}_{2} \mathrm{SO}_{4}$. Hydrogen peroxide $\left(\mathrm{H}_{2} \mathrm{O}_{2}\right)$ is then added to decompose excess permanganate ions, which can act as contaminants in the form of manganese ions $\mathrm{Mn}^{4+}[42,43]$. It should be noted that all previous procedures produce hazards due to the formation of toxic $\mathrm{NO}_{2}, \mathrm{~N}_{2} \mathrm{O}_{4}$, and/or $\mathrm{ClO}_{2}$ gas. Luo et al. demonstrated that the preexfoliation of graphite via microwave heating helped to remove intercalated species and improved oxygen absorption in subsequent Hummers processing [44]. In 2010, Marcano et al. [45] described an alternative approach to produce graphene oxide that has significant advantages over the Hummers method, with the improved efficiency of the oxidation process and no toxic gas produced during the chemical reactions. The protocol for running this reaction was the exclusion of using sodium nitrate $\left(\mathrm{NaNO}_{3}\right)$, increasing the amount of potassium permanganate $\left(\mathrm{KMnO}_{4}\right)$ and performing the reaction at 9:1 mixture of $\mathrm{H}_{2} \mathrm{SO}_{4} / \mathrm{H}_{3} \mathrm{PO}_{4}$. Microwave irradiation is also a powerful technique to reduce graphite oxide for getting reduced graphene oxide (rGO). Hu et al. have studied the effect of microwave irradiation on graphite oxide (GO) [46]. They have reported that the increase in oxygen content in GO decreases the activity of radiation absorption because of the reduction of the size of $\pi-\pi$ bonding. Hence, the reduction of GO to rGO becomes less effective. The reduction of GO starts from the unoxidized part of GO. As a result, graphene was more sensitive to microwave radiation compared to GO. It was observed that a small amount addition of graphene with GO leads to greater absorption of radiation and increases the deoxygenation process. In another study, microwave-irradiated graphene aerogel was prepared from GO, which was very low in density and highly compressible in nature [47].

Graphene has become one of the most attractive subjects due to its several breakthroughs in fundamental research and some promising practical applications [42, 48-55]. The interlayer spacing in a graphene oxide electrode (more than $0.625 \mathrm{~nm}$ ) allows the hydrated $\mathrm{Na}^{+}$ion, which has a radius of $0.358 \mathrm{~nm}$, to enter into the electrodes [45]. The abovementioned attractive properties of graphene make it feasible as electrode materials for the CDI system. Li et al. have pioneered the application of graphene as an electrosorption electrode material for the CDI system in 2009 [56]. The graphene was fabricated by the modified Hummers method followed by a hydrazine reduction process and was employed as the electrode for an electrosorption application. Batch-mode electrosorption experiments with good repeatability in $\mathrm{NaCl}$ solutions were conducted where high ion removal efficiency was achieved at high applied voltage $2.0 \mathrm{~V}$ and volume flow rate $40 \mathrm{~mL} / \mathrm{min}$. The result showed that the graphene exhibited high specific electrosorption capacities of $1.85 \mathrm{mg} / \mathrm{g}$ and $22.04 \mathrm{mg} / \mathrm{g}$ using feed concentrations of $22.5 \mathrm{mg} / \mathrm{L}$ and $490 \mathrm{mg} / \mathrm{L}$, respectively. In 2012, Li et al. have used reduced graphene oxide ( $\mathrm{rGO}$ ) nanoflakes to enhance the specific capacitance of activated carbon (AC) [57] and carbon nanotubes (CNTs) [58]. It was synthesized using $10 \mathrm{wt} \%$ graphene by a facile chemical synthesis method. The best electrochemical performance of this composite electrode gave a specific 
capacitance of $311 \mathrm{~F} / \mathrm{g}$, which is much higher than the CNT electrode $(202 \mathrm{~F} / \mathrm{g})$ in the $1 \mathrm{M} \mathrm{NaCl}$ solution at a scan rate of $10 \mathrm{mV} / \mathrm{s}$. The electrosorption capacity of composite and CNT electrodes using the $25 \mathrm{mg} / \mathrm{L} \mathrm{NaCl}$ solution was nearly the same: 0.88 and $0.87 \mathrm{mg} / \mathrm{g}$, respectively. The conditions used were $1.6 \mathrm{~V}$ and $25 \mathrm{~mL} / \mathrm{min}$ volume flow rate, but the time of electrode saturation in a single adsorption cycle decreased to half in the composite electrode compared to the CNT electrode, which took around 1 hour. In 2013, Wimalasiri and Zou made graphene electrodes for CDI using the modified Hummers method as stated by Marcano et al. [45] and then $9 \mathrm{wt} \%$ of SWCNT was combined with GO nanosheets, not only to increase the interlayer distance but also to contribute to the overall surface area and conductivity of the active material [59]. The specific surface area of graphene and the CNT/rGO composite was 362 and $391 \mathrm{~m}^{2} / \mathrm{g}$, respectively, and the mean pore diameter of graphene increased from $4.38 \mathrm{~nm}$ to $5.0 \mathrm{~nm}$ of the $\mathrm{CNT} / \mathrm{rGO}$ composite. Moreover, the specific capacitance of the CNT/GO composite was increased from $140 \mathrm{~F} / \mathrm{g}$ to $220 \mathrm{~F} / \mathrm{g}$ for the graphene electrode when measured at a $5 \mathrm{mV} / \mathrm{s}$ scan rate using the $1 \mathrm{M}$ $\mathrm{NaCl}$ solution. Furthermore, the electrosorption capacity of the CNT/rGO composite was $26.42 \mathrm{mg} / \mathrm{g}$, which was comparatively higher than graphene $(22.27 \mathrm{mg} / \mathrm{g})$ when measured using the $\mathrm{NaCl}$ solution at the initial concentration $780 \mathrm{mg} / \mathrm{L}$, volume flow rate $25 \mathrm{~mL} / \mathrm{min}$, and cell voltage $2.0 \mathrm{~V}$. In addition, the CNT/rGO composite-based electrodes demonstrated considerably faster salt adsorption and desorption cycles within an average of $62 \mathrm{~min}$ compared to graphene-based electrodes, which required $112 \mathrm{~min}$, for a single adsorption and desorption cycle.

In this study, our aim is to prepare $3 \mathrm{D}$ electrode materials based on acid-functionalized single-walled carbon nanotubes (a-SWCNT) and mwGO using RVC as a substrate and check their performance in a CDI system using a feed stream flowing directly through the electrodes. The performance of the electrodes was tested at different working conditions like flow rate and bias potential, which were optimized. Furthermore, the electrosorption isotherms like Langmuir and Freundlich models were investigated to describe how ions interact with electrodes. The performance of electrodes was evaluated through the electrosorption dynamic study. All the characteristics are very important to develop electrode materials for using effectively in desalination technology.

\section{Materials, Methods, and Characterizations}

2.1. Materials. The commercial SWCNT (Hipco-CCNI/Lot \# p1001) and graphite powder were supplied by Carbon Nanotechnologies, Inc. (Houston, TX) and Bay Carbon, Inc., respectively, and those were used as received. The chemicals DMF, $\mathrm{HNO}_{3}$ (70\%), $\mathrm{KMnO}_{4}, \mathrm{C}_{2} \mathrm{H}_{5} \mathrm{OH}$, and $\mathrm{NaCl}$ were procured from Sigma-Aldrich. In addition, the chemicals like $\mathrm{H}_{2} \mathrm{SO}_{4}(98 \%, w / v), \mathrm{H}_{2} \mathrm{O}_{2}$ (30\% aqueous), and $\mathrm{HCl}(36 \%$, $w / v)$ were purchased from Univar. All these chemicals were analytical reagent (AR) grade and were also used as received. The RVC (compressed 60 ppi (pores per inch)) was procured from ERG Materials and Aerospace Engineering Limited. The membrane filters $(0.2 \mu \mathrm{m}$ pore size GTTP) were supplied by Millipore. Milli-Q water, having electrical resistivity $18.2 \mathrm{~m} \Omega / \mathrm{cm}$, was used in all preparation methods.

2.2. Methods. In this study, the SWCNT was functionalized by treating with nitric acid (a-SWCNT) and graphene oxide (GO) was synthesized by the modified Hummers method as described by Marcano et al. [45]. The GO was exfoliated and reduced by the microwave irradiation (mwGO) technique [60]. Both the mwGO and a-SWCNT were dispersed in DMF and then mixed together to prepare the aSWCNT/mwGO composite coating solutions at different weight ratios. The a-SWCNT, mwGO, and prepared aSWCNT/mwGO composites were dip coated on an optimized RVC substrate to prepare different electrodes. Pretreatment of RVC was done with nitric acid to remove any traces of impurity from its surface before dip coating. The details of these processes are given in the Supplementary section from S1 to S8.

2.3. Characterizations. The electrochemical characterizations of base materials and their composite electrodes were performed by cyclic voltammetry $(\mathrm{CV})$. The measurement was done using the three-electrode system setup. The aSWCNT/RVC, mwGO/RVC, or a-SWCNT/mwGO/RVC acted as the working electrode (WE) in the $1 \mathrm{M} \mathrm{NaCl}$ aqueous solution over the voltage range -0.2-1.0 V; RVC electrode and $\mathrm{Ag} / \mathrm{AgCl}(3 \mathrm{M} \mathrm{NaCl})$ acted as the counter electrode (CE) and reference electrode (RE), respectively. For the CDI characterization, Pt electrode was used as a CE to avoid any chance of limiting the performance of the other composite electrodes. The measurement was performed at the scan rate of $5,10,20,50,100$, and $200 \mathrm{mV} / \mathrm{s}$. A platinum wire was used to make contact between $\mathrm{WE}$ and $\mathrm{CE}$.

The desalination experiments were performed within a flow-through electrode system using a capacitive deionization (CDI) cell. In this measurement, the total volume and concentration of the $\mathrm{NaCl}$ solution were $70 \mathrm{~mL}$ and $75 \mathrm{mg} / \mathrm{L}$, respectively. The distance between electrodes was $5 \mathrm{~mm}$, and the solution temperature was maintained at $293 \mathrm{~K}$. The total desalination processes, which involve the measuring of the amount of ion removal from the $\mathrm{NaCl}$ aqueous solution, the construction of a capacitive deionization (CDI) cell, measuring the effect of flow rate and voltage on ion removal efficiency, and the calculation of electrosorption capacity, are described within supplementary sections S9-S12.

\section{Results and Discussion}

3.1. Adsorption Performance of the 9-CNT/mwGO-Coated $R V C$ Electrode. The adsorption performance test was carried out at the optimum applied voltage $1.5 \mathrm{~V}$ (in this study, the ferricyanide solution was used to test the 3 electrode system. We observed the oxidation peak shift to $0.59 \mathrm{~V}$, where the ideal oxidation peak was $0.29 \mathrm{~V}$. Hence, the maximum/optimum applied voltage for our CDI system was $1.5 \mathrm{~V}$.) and optimum flow rate $50 \mathrm{~mL} / \mathrm{min}$, as reported in our previous study for the CNT/RVC electrode $[61,62]$. These conditions were used in further studies to compare the desalination performance of a range of electrodes with different amounts of 
Absorption behaviour of various composite 9-CNT/mwGO/RVC electrodes at $1.5 \mathrm{~V}$, using $50 \mathrm{~mL} / \mathrm{min}$ flow rate.

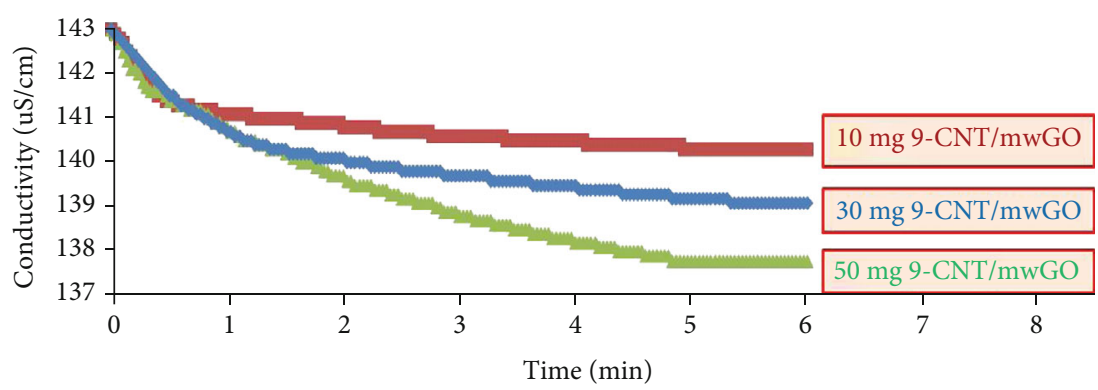

(a)

Electrosorption of 9-CNT/mwGO/RVC electrode in capacitive deionization sysytem

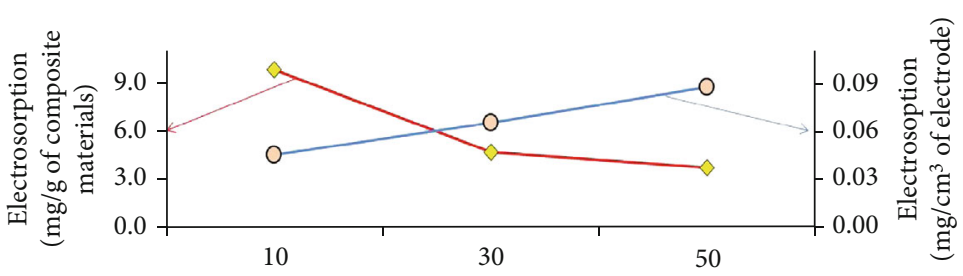

Loading weight of 9 a-SWCNT:1 mw GO coated RVC coated RVC electrode (mg).

(b)

FIGURE 1: (a) Adsorption behaviour and (b) the electrosorption capacity in terms of the mass of composite material loading and the geometric volume of the electrode of various 9-CNT/mwGO/RVC electrodes. Loadings (mg): 10, 30, and 50.

9-CNT/mwGO composite materials coated on the RVC electrode. All experiments were performed by keeping the total volume of the $\mathrm{NaCl}$ solution at $70 \mathrm{~mL}$ and the initial feed concentration at $75 \mathrm{mg} / \mathrm{L}(143 \mu \mathrm{S} / \mathrm{cm})$. Figure $1(\mathrm{a})$ shows the CDI process for all loading level composites at the geometric volume $2.16 \mathrm{~cm}^{3}$ of the RVC electrode: 10,30 , and $50 \mathrm{mg}$ loadings. There is a drop in the conductivity of the test saline solution with increasing amounts of material on the electrode because ions were attracted by the oppositely charged electrodes when an electric field was applied [63]. A better electrosorption performance was achieved at $50 \mathrm{mg}$ coated RVC electrode where the conductivity was significantly dropped by approximately $5.21 \mu \mathrm{S} / \mathrm{cm}$ in the electrosorption process. Figure 1(b) shows the electrosorption of various $9-\mathrm{CNT} / \mathrm{mwGO} / \mathrm{RVC}$ electrodes in terms of the mass of $9-\mathrm{CNT} / \mathrm{mwGO}$ and the volume of electrode (calculated as per supplementary section S12). It is evident from the figure that the electrosorption capacity was decreased with the increase in weight of composite material. It is clear that when the RVC electrode was loaded with $10 \mathrm{mg}$ of composite, the electrosorption capacity was $9.91 \mathrm{mg} / \mathrm{g}$ and when the same electrode was loaded with $50 \mathrm{mg}$ of composite, the electrosorption capacity became $3.82 \mathrm{mg} / \mathrm{g}$. On the contrary, the electrosorption capacity of electrodes in terms of geometric volume was increased with the increase in amount of composite material. The calculation showed that when the RVC electrode was separately loaded with $10 \mathrm{mg}$ and $50 \mathrm{mg}$ of composites, the electrosorption capacities were $0.05 \mathrm{mg} / \mathrm{cm}^{3}$ and $0.09 \mathrm{mg} / \mathrm{cm}^{3}$, respectively. This result leads to the generalization that the electrosorption capacity increases with increasing amounts of material on the electrode.
3.2. Optimization of Conditions for Ion Removal Efficiency. This study is based on the $50 \mathrm{mg}$ 9-CNT/mwGO composite-coated RVC electrode because it showed the highest electrosorption capacity in terms of geometric volume. The optimization was carried out for electrical voltage and flow rate. The investigated cell voltages were $1.3 \mathrm{~V}$ and $1.5 \mathrm{~V}$, and the flow rates were $25 \mathrm{~mL} / \mathrm{min}, 50 \mathrm{~mL} / \mathrm{min}$, and $75 \mathrm{~mL} / \mathrm{min}$ as shown in Figures 2(a) and 2(b). Cell voltages above $1.5 \mathrm{~V}$ were not investigated because saving energy is one of our targets. Figure 2(a) represents the variation solution conductivity with respect to time at two different voltages. It was observed that with the increase in applied voltage, the ion removal amount was also increased. Hence, higher ion removal was achieved at $1.5 \mathrm{~V}$. Figure $2(\mathrm{~b})$ shows that the highest variation in solution conductivity was observed at a $50 \mathrm{~mL} / \mathrm{min}$ flow rate, which indicated the highest electrosorption capacity. This is because a low pump rate would result in an obvious coion effect, which will suppress the electrosorption process, while a high pump rate will introduce a high pump force that is greater than that of electrosorption force and therefore decrease the electrosorption amount [64]. Thus, the optimized cell voltage and flow rate for the CDI process were found to be $1.5 \mathrm{~V}$ and $50 \mathrm{~mL} / \mathrm{min}$, respectively.

\subsection{Capacitive Deionization (CDI) System}

3.3.1. Adsorption/Desorption Performance of the CNT/mwGO/RVC Electrodes. The CDI system was investigated with respect to the influence of increasing ratios of mwGO in the $\mathrm{CNT} / \mathrm{mwGO}$ composite material-coated 
Adsorption behaviour of $50 \mathrm{mg}$ composite $9-\mathrm{CNT} / \mathrm{mwGO} / \mathrm{RVC}$ electode at 50 $\mathrm{mL} / \mathrm{min}$ flow rate, at various voltages, used $75 \mathrm{mg} / \mathrm{L} \mathrm{NaCl}$ solution.

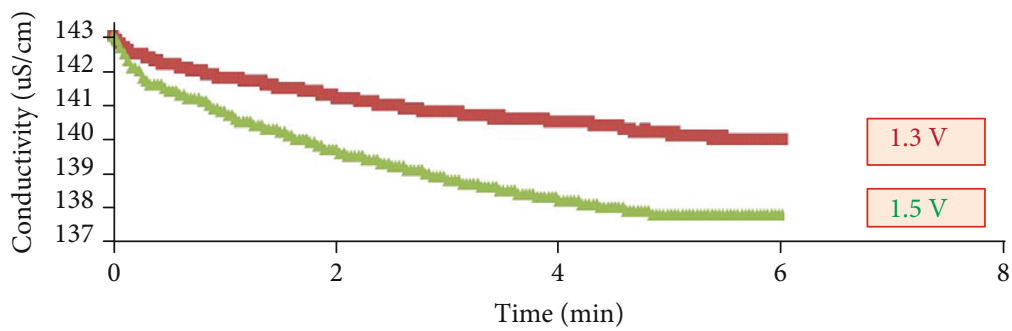

(a)

Adsorption behaviour of $50 \mathrm{mg}$ composite 9-CNT/mwGO/RVC electrode at various flow rate, at $1.5 \mathrm{~V}$ used $75 \mathrm{mg} / \mathrm{L} \mathrm{NaCl}$ solution.

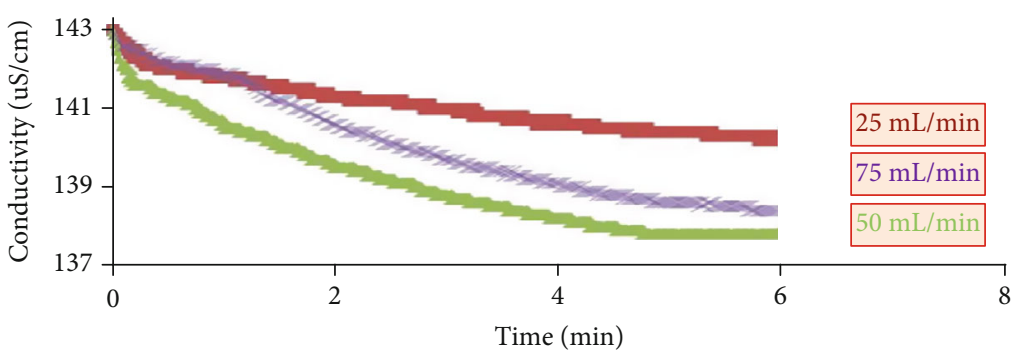

(b)

FIGURE 2: Conductivity variations of the $\mathrm{NaCl}$ solution with various (a) applied voltages and (b) applied flow rates, with respect to operating time, using the $9-\mathrm{CNT} / \mathrm{mwGO} / \mathrm{RVC}$ electrode loaded with $50 \mathrm{mg}$ composite material.

RVC electrodes on the ion removal performance. The ratio levels were 10:0, 9:1, 8:2, and 7:3 CNT:mwGO, respectively, and the mass of materials coated on all RVC electrodes was $50 \mathrm{mg}$. All experiments were performed with the same previous conditions at $1.5 \mathrm{~V}$ and $50 \mathrm{~mL} / \mathrm{min}$ flow rate with $6 \mathrm{~min}$ adsorption processes. Figure 3(a) shows the CDI process for all composite-coated RVC electrodes. As expected, once the electrical voltage was applied, the solution conductivity dramatically decreased for all electrodes because ions were attracted by opposite charges on the electrodes [63]. Then, the conductivity would gradually approach a constant minimum level, indicating that saturation was achieved [58]. During the discharging of the CDI system under $0 \mathrm{~V}$ of applied voltage, the solution conductivity was returned to approximate its initial value $(143 \mu \mathrm{S} / \mathrm{cm})$, meaning that the ions were released from the double layer region back into the solution because of the disappearance of electrostatic forces. It is clear that the highest drop in conductivity was around $5.2 \mu \mathrm{S} / \mathrm{cm}$ using the $9-\mathrm{CNT} / \mathrm{mwGO} / \mathrm{RVC}$ electrode. The second-largest drop in conductivity was around $4.8 \mu \mathrm{S} / \mathrm{cm}$ using the $8-\mathrm{CNT} / \mathrm{mwGO} / \mathrm{RVC}$ electrode. The drop in conductivity for the CNT/RVC electrode was higher than that of the $7-\mathrm{CNT} / \mathrm{mwGO} / \mathrm{RVC}$ electrode. It is notable that the 9-CNT/mwGO/RVC electrode's saturation was achieved after $5 \mathrm{~min}$, whereas the CNT/RVC electrode saturation was achieved after $6 \mathrm{~min}$. It is also interesting to note that the regeneration by discharging the CDI cells was completed, at $0 \mathrm{~V}$, after $13 \mathrm{~min}$ for the electrode with the least amount of the mwGO ratio in the sample that is 9$\mathrm{CNT} / \mathrm{mwGO} / \mathrm{RVC}$. However, for the CNT/RVC electrode, the required time for one electrosorption-desorption process was $18 \mathrm{~min}$. Hence, there was $27.78 \%$ saving of time in one desalination cycle for the 9-CNT/mwGO/RVC electrode compared to the CNT/RVC electrode [61]. Moreover, the electrosorption capacities in terms of mass of electrode for 9-CNT/mwGO/RVC and CNT/RVC electrodes were $3.82 \mathrm{mg} / \mathrm{g}$ and $3.23 \mathrm{mg} / \mathrm{g}$, respectively. Thus, there was an $18.27 \%$ increment in the electrosorption removal performance for the 9-CNT/mwGO/RVC electrode compared to the CNT/RVC electrode. This improvement in electrosorption amount in the 9-CNT/mwGO/RVC electrode can be attributed to many complicated factors: these included the increasing specific surface area, specific capacitance, more accessible interlayer, pore microstructure, and pore size distribution which can play important roles in affecting the electrosorption capacity $[58,59,65]$.

Figure 3(b) shows the electrosorption performances of all electrodes which were measured from the data in Figure 3(a). The variation of the solution conductivity was monitored instantly by a multifunction conductivity meter. Accordingly, the correlation of conductivity $(\mu \mathrm{S} / \mathrm{cm})$ with concentration $(\mathrm{mg} / \mathrm{L})$ was calibrated prior to experiments (shown in supplementary section S9). Furthermore, the 8$\mathrm{CNT} / \mathrm{mwGO} / \mathrm{RVC}$ electrode also afforded better CDI system performance than the a-SWCNT/RVC electrode, as evidenced by time saving of the $11.11 \%$ and $8.98 \%$ better electrosorption removal of $\mathrm{NaCl}$. Table 1 also represents the detailed electrosorption in terms of mass, area, and volume for each composite electrode (calculated as per supplementary section S12). It is clear that the 
Adsorption behaviour of CNT/mwGo/RVC electrodes, loaded with $50 \mathrm{mg}$ of various ratios of $\mathrm{CNT} / \mathrm{mwGO}$, at $50 \mathrm{~mL} / \mathrm{min}$ flow rate, $1.5 \mathrm{~V}$ applied voltage, using $75 \mathrm{ppm} \mathrm{NaCl}$ feed solution

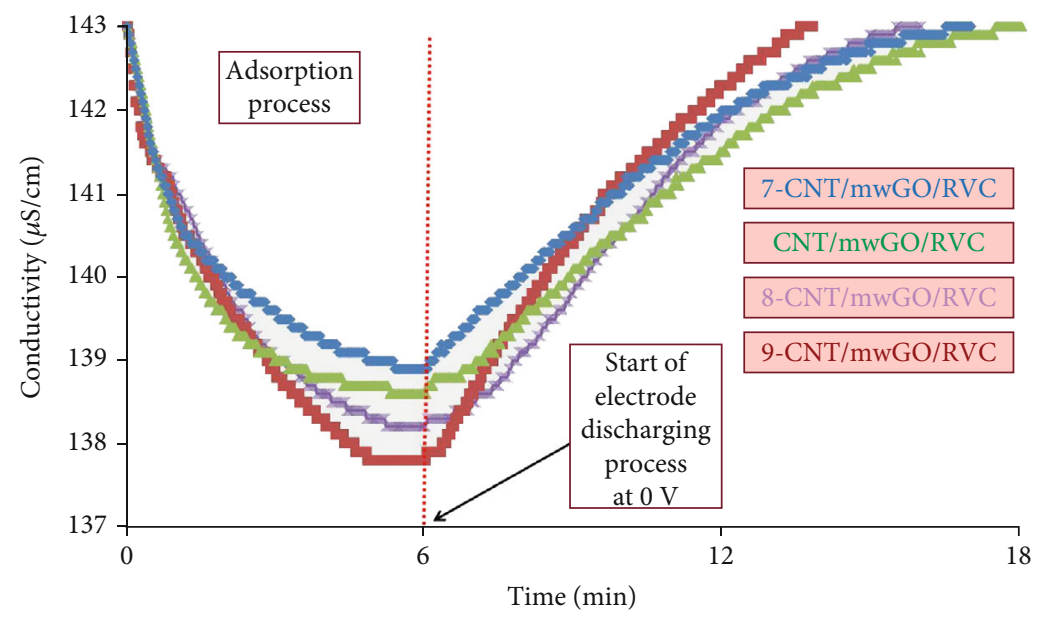

(a)

Electrosorption of $\mathrm{NaCl}$ by $\mathrm{CNT} / \mathrm{mwGO} / \mathrm{RVC}$ electrodes, loaded with $50 \mathrm{mg}$ of various ratios of $\mathrm{CNT} / \mathrm{mwGO}$

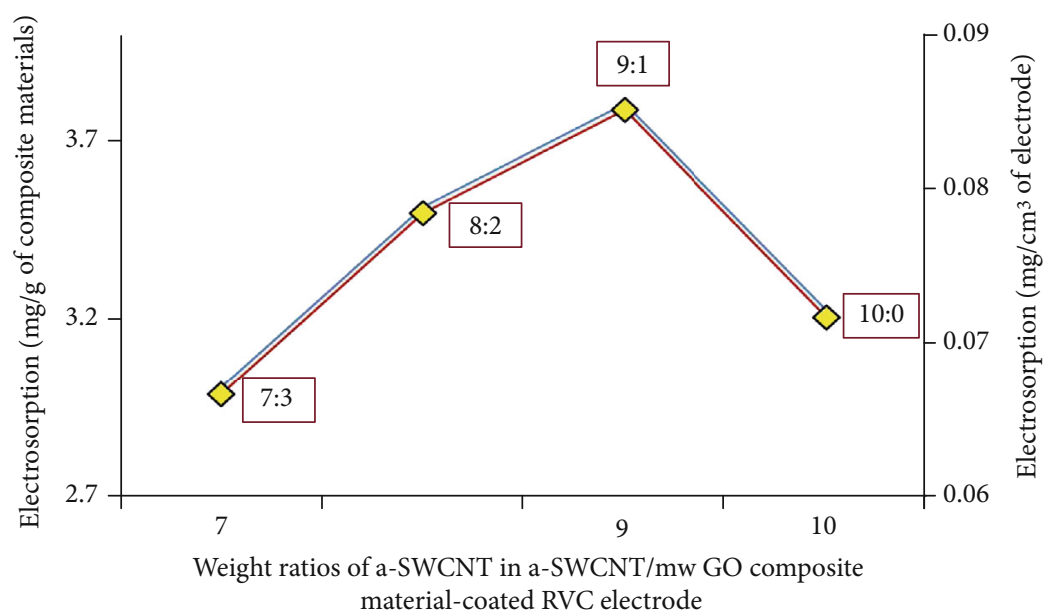

(b)

FIGURE 3: (a) Adsorption and release behaviour and (b) the electrosorption capacity in terms of mass of CNT/mwGO and the geometric volume of electrode of various ratios $10,9,8$, and $7 \mathrm{CNT}$ in $\mathrm{CNT} / \mathrm{mwGO} / \mathrm{RVC}$ electrodes.

TABLE 1: Electrosorption of $\mathrm{NaCl}$ by the CNT/mwGO/RVC electrodes with various ratios of CNT and time of one desalination cycle (* comparing with the CNT/RVC electrode).

\begin{tabular}{lccccc}
\hline \multirow{2}{*}{ Ratio of a-SWCNT in electrodes } & \multicolumn{3}{c}{ Electrosorption } \\
$\mathrm{mg} / \mathrm{g} / \mathrm{cm}^{2}$ & $\mathrm{mg} / \mathrm{cm}^{3}$ & $\begin{array}{c}{ }^{*} \text { Enhancement percentage in electrosorption } \\
\%\end{array}$ & $\begin{array}{c}\text { Time of one desalination cycle } \\
\mathrm{min}\end{array}$ \\
\hline 7 & 3.01 & $8.4 E-03$ & 0.07 & & 17 \\
8 & 3.52 & $9.9 E-03$ & 0.09 & 8.98 & 16.27 \\
9 & 3.82 & $1.1 E-02$ & 0.10 & & 13 \\
10 & 3.23 & $9.4 E-03$ & 0.08 & 18 \\
\hline
\end{tabular}

electrosorption behaviours of all composite electrodes in terms of area and in terms of volume followed the electrosorption behaviours of composite electrodes in terms of mass of electrode because all the parameters were held con- stant: mass of material, electrode area, and volume. These results suggested that the CDI process, using the 9$\mathrm{CNT} / \mathrm{mwGO} / \mathrm{RVC}$ electrode, was promising as an effective technology for desalination. 
Electrosorption of $\mathrm{NaCl}$ by $\mathrm{CNT} / \mathrm{mwGO} / \mathrm{RVC}$ electrodes, loaded with $50 \mathrm{mg}$ of various ratios of $\mathrm{CNT} / \mathrm{mwGO}$, at $1.5 \mathrm{~V}$ applied voltage and $50 \mathrm{~mL} / \mathrm{min}$ flow rate

7-CNT/mwGO/RVC

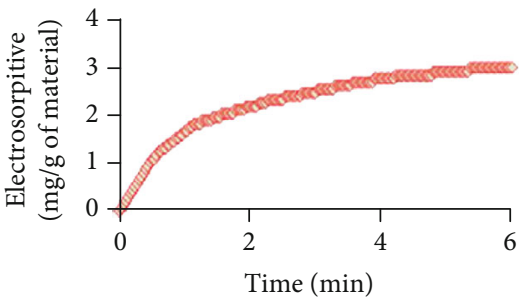

(a)

9-CNT/mwGO/RVC

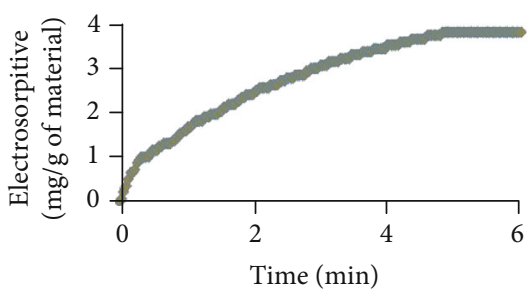

(c)

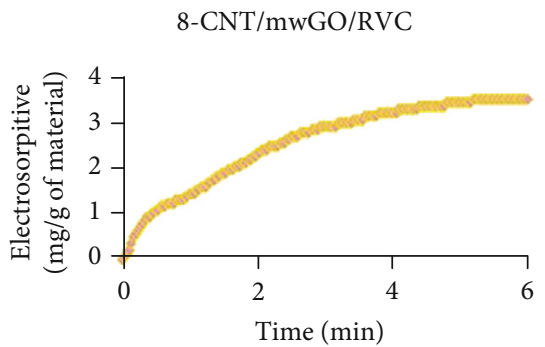

(b)

CNT/RVC

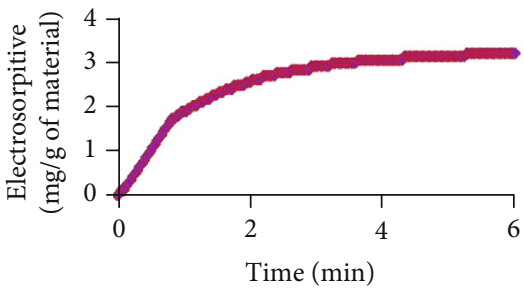

(d)

Pseudo-firt-order adsorption kinetics of electrosorption of $\mathrm{NaCl}$ by $\mathrm{CNT} / \mathrm{mwGO} / \mathrm{RVC}$ electrodes, loaded with $50 \mathrm{mg}$ of various ratios of $\mathrm{CNT} / \mathrm{mwGO}$ at $1.5 \mathrm{~V}$ applied voltage and $50 \mathrm{~mL} / \mathrm{min}$ flow rate

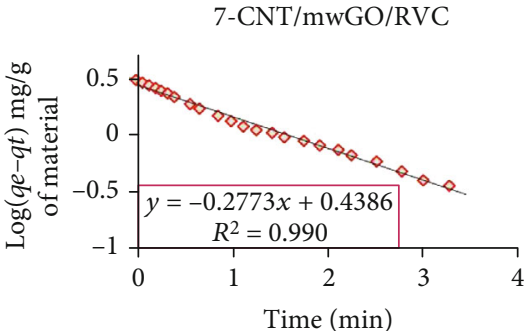

(e)

9-CNT/mwGO/RVC

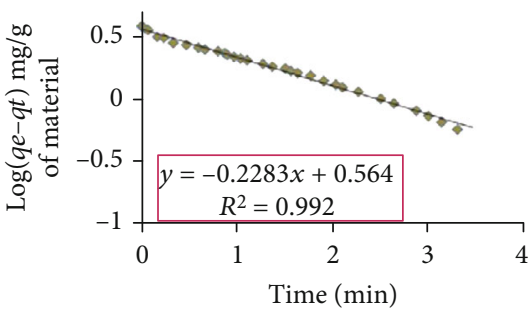

(g)

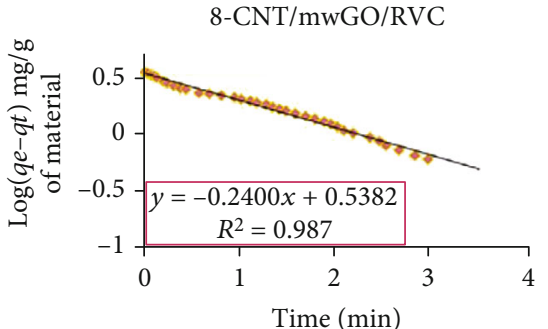

(f)

10a-SWCNT/RVC

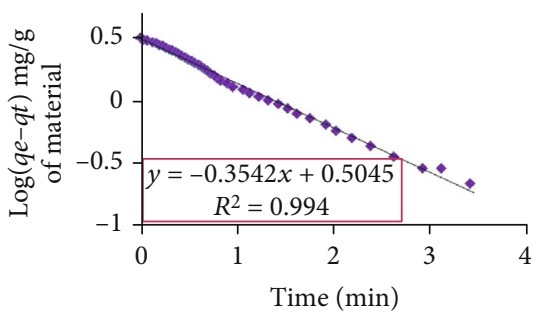

(h)

FIgure 4: (a-d) Electrosorption and (e-h) pseudo-first-order adsorption kinetics of the NaCl electrosorption onto CNT/RVC, 9$\mathrm{CNT} / \mathrm{mwGO} / \mathrm{RVC}, 8-\mathrm{CNT} / \mathrm{mwGO} / \mathrm{RVC}$, and 7-CNT/mwGO/RVC electrodes, respectively, at $1.5 \mathrm{~V}$ and $50 \mathrm{~mL} / \mathrm{min}$ flow rate. Results have been derived from Figure 5.15 (a) (adsorption process).

3.3.2. Electrosorption Dynamics. The performance of electrode adsorptions is evaluated by dynamics study, which describes the solute uptake rate, and evidently, this rate controls the residence time of adsorptive uptake at the solid-solution interface $[66,67]$. However, this section will investigate the controlling mechanism of electrosorption and the constants of sorption of pseudo-first-order kinetics as proposed by Lagergren [68], where the conformity between experimental data and the model's predicted values is expressed by the correlation coefficients $\left(r^{2}\right.$, values close or equal to 1). The electrosorption dynamic and pseudo-firstorder dynamic models for the $\mathrm{NaCl}$ adsorption onto CNT/RVC, 9-CNT/mwGO/RVC, 8-CNT/mwGO/RVC, and 7-CNT/mwGO/RVC electrodes at voltage $1.5 \mathrm{~V}$, flow rate $50 \mathrm{~mL} / \mathrm{min}$, and constant temperature $298 \mathrm{~K}$ are presented in Figure 4. The composite electrodes (except 9$\mathrm{CNT} / \mathrm{mwGO} / \mathrm{RVC}$ ) exhibited steady increment in electrosorption within the first minute, then it became dynamic 
TABLE 2: The comparison between the adsorption rate constant $\left(k_{1}\right)$ and correlation coefficients of pseudo-first-order kinetics and the estimated theoretical and experimental $\left(q_{e}\right)$ maximum electrosorption with the pseudo-first-order model.

\begin{tabular}{lcccc}
\hline a-SWCNT $:$ mwGO & $R^{2}$ & $K_{1}\left(\mathrm{~min}^{-1}\right)$ & Theoretical $q_{e}(\mathrm{mg} / \mathrm{g})$ & Experimental $q_{e}(\mathrm{mg} / \mathrm{g})$ \\
\hline $7: 3$ & 0.990 & 0.639 & 2.75 & 3.01 \\
$8: 2$ & 0.987 & 0.555 & 3.45 & 3.52 \\
$9: 1$ & 0.992 & 0.525 & 3.66 & 3.82 \\
$10: 0$ & 0.994 & 0.816 & 3.19 & 3.23 \\
\hline
\end{tabular}

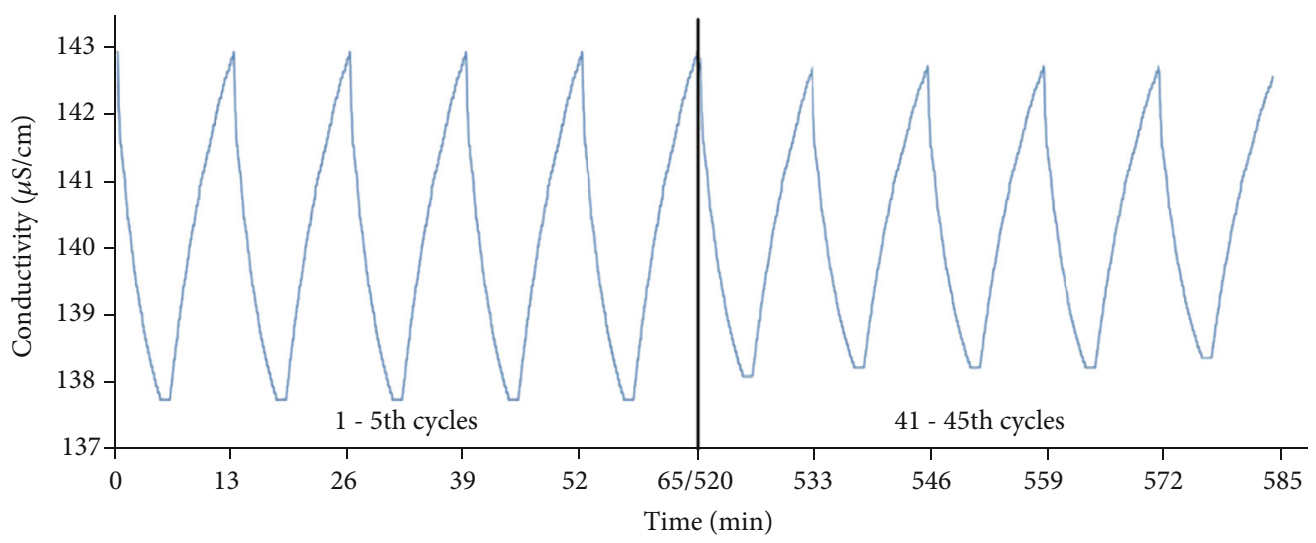

Figure 5: Multiple electrosorption-desorption cycles of the $75 \mathrm{mg} / \mathrm{L} \mathrm{NaCl}$ solution for the 9-CNT/mwGO/RVC electrode measured at $50 \mathrm{~mL} / \mathrm{min}$ flow rate through electrode upon polarization and depolarization at $1.5 \mathrm{~V}$ and $0 \mathrm{~V}$, respectively.

adsorption, and after three minutes, the electrode gradually approached saturation as shown in Figures 4(a), 4(b), and $4(\mathrm{~d})$. The time required to reach the adsorption equilibrium was 6 minutes. However, the electrosorption of $\mathrm{NaCl}$ onto the $9-\mathrm{CNT} / \mathrm{mwGO} / \mathrm{RVC}$ electrode was very rapid within the first half minute. This could be because the external surface area of bundled CNT in this electrode is higher than other electrodes, thus increasing the possibility of ions to reach the surface easily. After that, the electrosorption of $\mathrm{NaCl}$ onto this electrode becomes dynamic adsorption for four minutes and then followed by the electrode saturation as shown in Figure 4(c). The time required to reach adsorption equilibrium was 5 minutes, which may be due to the higher rate of diffusion of ions onto the electrode particle surface.

The pseudo-first-order kinetics for all electrodes was studied within the first four minutes as shown in Figures 4(e)-4(g) and 4(d), respectively. To evaluate the kinetics of the electrosorption process, the pseudo-first-order model was tested to interpret the experimental data. The pseudo-first-order equation has been expressed in Supplementary section S13. The slopes and intercepts of plots of $\log \left(q_{e}-q_{t}\right)$ versus $t$ were used to determine the first-order rate constant $k_{1}$. In all electrodes, methods that are based on the linearization of the models and correlation coefficients $\left(r^{2}\right)$ of around 0.99 confirm that all electrodes followed pseudo-first-order dynamics. Similar trends were reported in the literature for the adsorption of $\mathrm{NaCl}$ ions from aqueous solutions by other adsorbents [56, $64,69-73]$. A comparison of the rate constant $k_{1}$ with the correlation coefficients is shown in Table 2 . The rate constant $\left(k_{1}\right)$ of the pseudo-first-order kinetics was $0.816,0.525,0.555$, and $0.639 \mathrm{~min}^{-1}$ for $\mathrm{CNT} / \mathrm{RVC}$, 9-CNT/mwGO/RVC, 8$\mathrm{CNT} / \mathrm{mwGO} / \mathrm{RVC}$, and 7-CNT/mwGO/RVC electrodes, respectively. Hence, it is clear that there is an inverse relationship between the rate constant and electrosorption; when the electrosorption capacity is increased, the rate constant is decreased. Also, the theoretical $q_{e}$ values found from the pseudo-first-order kinetics model gave reasonable values (3.19, 3.66, 3.45, and $2.75 \mathrm{mg} / \mathrm{g}$ for $\mathrm{CNT} / \mathrm{RVC}$, 9$\mathrm{CNT} / \mathrm{mwGO} / \mathrm{RVC}, \quad 8-\mathrm{CNT} / \mathrm{mwGO} / \mathrm{RVC}$, and 7$\mathrm{CNT} / \mathrm{mwGO} / \mathrm{RVC}$ electrodes, respectively).

3.3.3. CDI Cycling Stability. The regeneration of electrodes plays a significant role in their commercialization for using in CDI systems. To test reversibility, the 9-CNT/mwGO/RVC electrode was selected because it had the highest electrosorption capacity among all the electrodes. Several charging and discharging cycles for this electrode are presented in Figure 5. The figure clearly shows that no oxidation and reduction reactions occur in electrosorption. This indicates that the consumption of current is mainly because of charging the electrode where the ions are electroadsorbed from the bulk solution [74], and there is complete formation of electrical double layer at the electrode and electrolyte interface [75]. Moreover, the conductivity changes are reproducible for the first five cycles of electrosorption and desorption, confirming that the CDI could be regenerated very well without any driving energy and secondary pollution, which is critical for large-scale applications. It is observed from the figure that the regeneration test can be performed in a short period of time because the same pattern is noticed when considered 
The electrosorption isotherm for 9-CNT/mwGO/RVC and CNT/RVC electrodes at $1.5 \mathrm{~V}$ and $50 \mathrm{~mL} / \mathrm{min}$ flow rate.

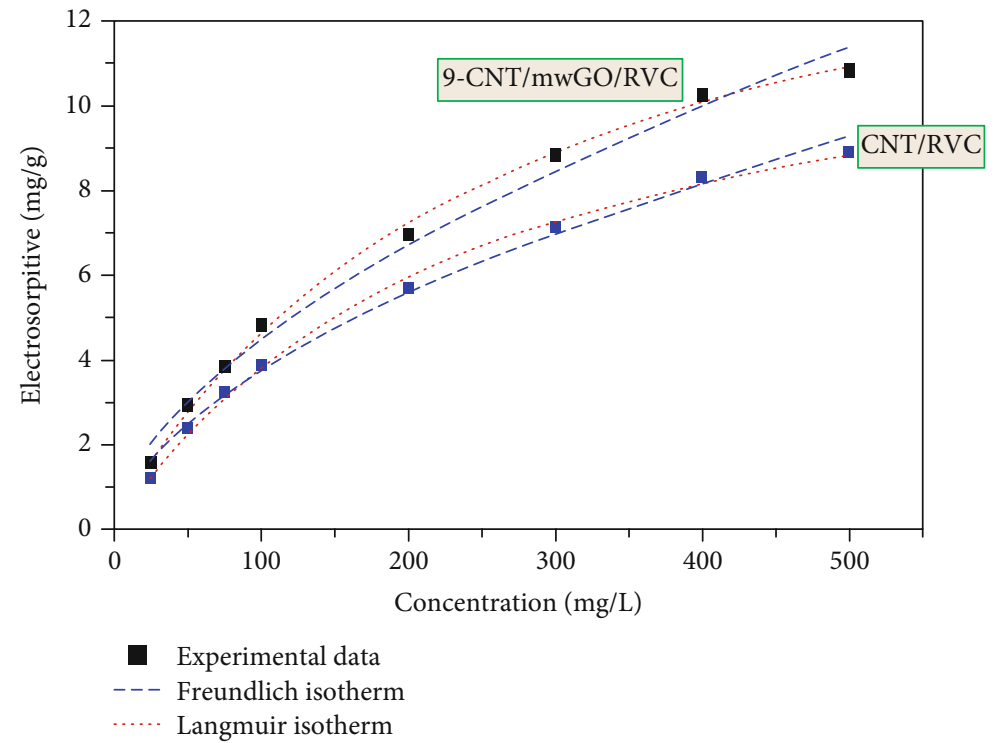

Figure 6: The electrosorption isotherms for 9-CNT/mwGO/RVC and CNT/RVC electrodes at $1.5 \mathrm{~V}$ and $50 \mathrm{~mL} / \mathrm{min}$ flow rate using different initial concentrations of the $\mathrm{NaCl}$ solutions.

for four repeated electrosorption-desorption cycles; each cycle takes $13 \mathrm{~min}$ that is $6 \mathrm{~min}$ of ion adsorption and $7 \mathrm{~min}$ release of ions. Initially, for the first five cycles, the electrode showed very high recycling stability (100\%) because of no decay of the electrosorption capacity. This type of high cycling stability behaviour of the CNT/GO electrode in a CDI system is reported in other research as well as when tested for four cycles [58]. It is observed from the figure that during 41-45 cycles, the amplitude of conductivity is less compared to the first five cycles. This indicates that the electrosorption capacity during higher cycles becomes worse, and there is the degradation of the CDI performance.

3.3.4. Electrosorption Isotherm. The electrosorption isotherm is generally used to describe how ions interact with carbon electrodes. The Langmuir and Freundlich isotherms are the two most common isotherms, and they were employed for simulating the ion adsorption on the $9-\mathrm{CNT} / \mathrm{mwGO} / \mathrm{RVC}$ electrode. The electrosorption isotherms of $\mathrm{NaCl}$ onto the 9-CNT/mwGO/RVC electrode were evaluated, and their results were compared with the results of the CNT/RVC electrode. This experiment was performed using the different concentrations of $\mathrm{NaCl}$ as presented in Figure 6. It is observed from the figure that the trend of the electrosorption capacity behaviour of both electrodes is the same and differs only in their magnitude. For both electrodes, the removal of $\mathrm{NaCl}$ has increased with the increase in concentration. This can be attributed to the enhancement of ions' mass transfer rate inside the microporous electrodes $[71,76,77]$. The figure shows that the electrosorption capacity of 9$\mathrm{CNT} / \mathrm{mwGO} / \mathrm{RVC}$ and CNT/RVC electrodes is 10.84 and $8.89 \mathrm{mg} / \mathrm{g}$, respectively, at $500 \mathrm{mg} / \mathrm{L}$ feed concentration. This implies that combining mwGO with CNT materials has
TABLE 3: The parameters of Langmuir and Freundlich isotherms for the $\mathrm{NaCl}$ electrosorption using the 9-CNT/mwGO/RVC and $\mathrm{CNT} / \mathrm{RVC}$ electrodes.

\begin{tabular}{lccc}
\hline Isotherm & Parameter & $\begin{array}{c}\text { Value } \\
\text { 9-CNT/mwGO/RVC }\end{array}$ & $\begin{array}{c}\text { Value }^{*} \\
\text { CNT/RVC }\end{array}$ \\
\hline \multirow{3}{*}{ Langmuir } & $q_{m}(\mathrm{mg} / \mathrm{g})$ & 16.59 & 13.08 \\
& $K_{L}(\mathrm{~L} / \mathrm{mg})$ & 0.01 & 0.01 \\
& $\mathrm{R}^{2}$ & 0.995 & 0.997 \\
\hline \multirow{3}{*}{ Freundlich } & $K_{F}(\mathrm{~L} / \mathrm{mg})$ & 0.32 & 0.28 \\
& $n$ & 1.74 & 1.74 \\
& $R^{2}$ & 0.981 & 0.989 \\
\hline
\end{tabular}

${ }^{*}$ These results were calculated in article [61].

increased the number of adsorption sites in the 9$\mathrm{CNT} / \mathrm{mwGO} / \mathrm{RVC}$ electrode under an electric field. Langmuir and Freundlich isotherms (shown in Supplementary section S14) were used to fit the experimental data for electrosorption of $\mathrm{Na}^{+}$and $\mathrm{Cl}^{-}$onto the electrodes. The Langmuir isotherm is applicable to localized adsorbed ions with a limited adsorption amount [78], and the Freundlich isotherm is suitable for the description of ion adsorption with a wide variety of adsorption strength [79].

Table 3 shows the comparison between Langmuir and Freundlich isotherms for the $\mathrm{NaCl}$ electrosorption using both electrodes. It is revealed that the electrosorption isotherm of both electrodes obeys both models, when considering the $R^{2}$ values (better than $99.9 \%$ confidence level). The regression coefficients for CNT/RVC were 0.997 and 0.989 and for the 9-CNT/mwGO/RVC electrode were 0.995 and 0.981 for the Langmuir and Freundlich isotherms, 


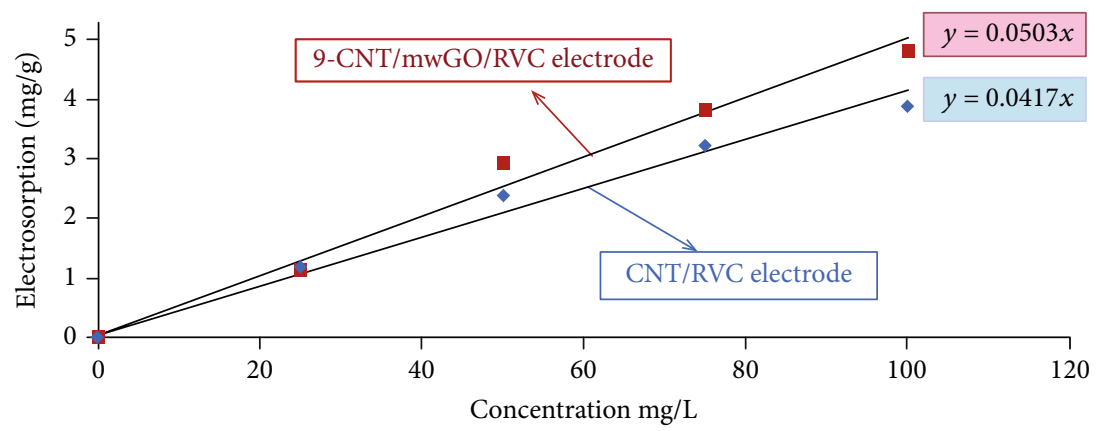

(a)

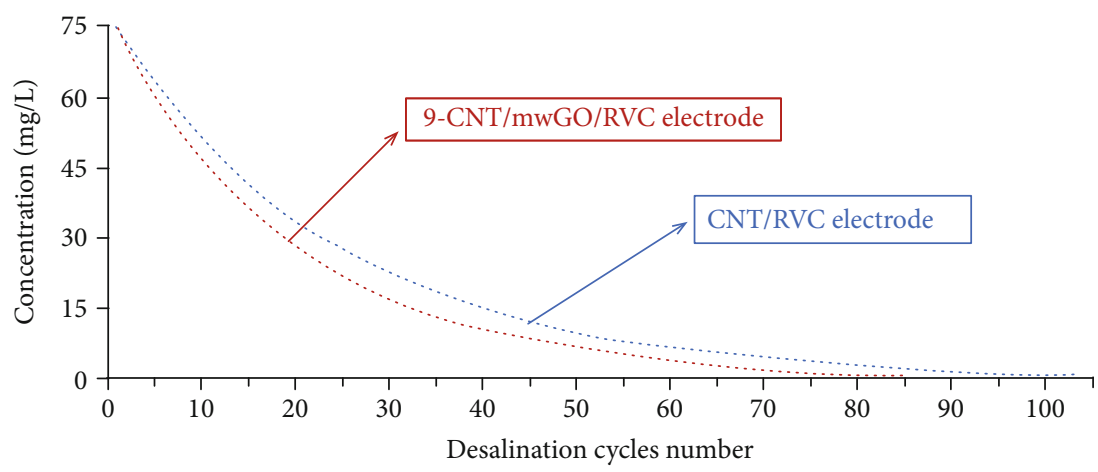

(b)

Figure 7: (a) The variation of electrosorption with respect to feed concentration and (b) the variation of feed concentration with respect to desalination cycles.

respectively. These results suggest that the monolayer adsorption is the primary adsorption mechanism during the electrosorption process $[70,72]$. The $K_{L}$ values of both electrodes are 0.01, and the $K_{F}$ values of CNT/RVC and 9$\mathrm{CNT} / \mathrm{mwGO} / \mathrm{RVC}$ electrodes are 0.28 and 0.32 , respectively. Normally, a higher value of $n$ between 1 and 10 represents more beneficial adsorption [64], and the volume of $n$ for both electrodes was around 1.74. Hence, the electrodes with a high value of $n$ exhibit a high potential for electrosorption capability. In this type of system, the adsorbed layer is extremely thin, and the amount adsorbed is only a fraction of the monolayer capacity. Therefore, the electrosorption for both electrodes is followed by the monolayer adsorption [56]. Additionally, as a standard procedure, in order to calculate the maximum electrosorption amount of electrodes, the term $q_{m}$ in the Langmuir equation has been considered as the maximum adsorption capacity. The results show that the $q_{m}$ has improved with the increase in bias concentration. The $q_{m}$ measured at polarization of $1.5 \mathrm{~V}$ and a flow rate of $50 \mathrm{~mL} / \mathrm{min}$ was 13.08 and $16.59 \mathrm{mg} / \mathrm{g}$ using CNT/RVC and 9-CNT/mwGO/RVC electrodes, respectively. Hence, it can be suggested that the maximum adsorption capacity $q_{m}$ for $\mathrm{NaCl}$ on the $9-\mathrm{CNT} / \mathrm{mwGO} / \mathrm{RVC}$ electrode has improved compared to the CNT/RVC electrode. When considering a concentration of $500 \mathrm{mg} / \mathrm{L} \mathrm{NaCl}$, the $q_{m}$ at equilibrium for the CNT/RVC electrode is much higher compared to multiwalled carbon nanotubes (MWCNTs) [72] and activated carbon (AC) [80], which were $3.10 \mathrm{mg} / \mathrm{g}$ and $9.72 \mathrm{mg} / \mathrm{g}$, respectively. This is because the surface area and average pore size in the CNT/RVC electrode are larger, where the surface area in MWCNTs and AC electrodes was 153 and $1153 \mathrm{~m}^{2} / \mathrm{g}[72,80]$, respectively. In addition, the $q_{m}$ of the $\mathrm{CNT} / \mathrm{RVC}$ electrode is very close to the $q_{m}$ of composite made from carbon nanotubes and carbon nanofiber (CNTs-CNFs) electrode, which was $13.35 \mathrm{mg} / \mathrm{g}$ [71]. The maximum electrosorption capacity results of 9$\mathrm{CNT} / \mathrm{mwGO} / \mathrm{RVC}$ and CNT/RVC electrodes are lower than the graphene electrode, which was $21.04 \mathrm{mg} / \mathrm{g}$ [56]. This graphene electrode mainly consists of mesopores with an average pore diameter of about $7.42 \mathrm{~nm}$, which is greatly beneficial to a capacitive deionization system.

3.3.5. Water Production by a CDI System. The water production experiment and calculation were carried out at the $\mathrm{NaCl}$ feed solution concentration $75 \mathrm{mg} / \mathrm{L}$. It has been shown earlier that $1 \mathrm{~g}$ of the 9:CNT/mwGO composite and CNT coated on $43.20 \mathrm{~cm}^{3}$ RVC electrode adsorbed $3.82 \mathrm{mg}$ and $3.23 \mathrm{mg}$ $\mathrm{NaCl}$ during 13 mins and 18 mins, respectively. Hence, the solution concentration was reduced from $75 \mathrm{mg} / \mathrm{L}$ to $71.18 \mathrm{mg} / \mathrm{L}$ and $71.77 \mathrm{mg} / \mathrm{L}$ for 9:CNT/mwGO/RVC and CNT/RVC electrodes, respectively, after 1 desalination cycle. Moreover, it has also been shown that the electrosorption capacity varied with the increase in solution concentration and exhibits a linear relationship below the concentration of $100 \mathrm{mg} / \mathrm{L}$ (Figure 6). The abovementioned claim has been confirmed by their linear fit as shown in Figure 7(a) where plots for 9:CNT/mwGO/RVC and CNT/RVC composite electrodes are based on Equations (1) and (2), respectively. 
For the 9:CNT/mwGO/RVC composite electrode,

Electrosorption $(\mathrm{mg} / \mathrm{g})=0.050 *$ concentration.

For the CNT/RVC composite electrode,

$$
\text { Electrosorption }(\mathrm{mg} / \mathrm{g})=0.042 * \text { concentration. }
$$

From these equations, the variation of concentration can be known after each desalination cycle. Figure 7(b) represents the variation of concentration with respect to the desalination cycle. The reading was noted till the concentration was reached less than $1 \mathrm{mg} / \mathrm{L}$ using $1 \mathrm{~g}$ of the $\mathrm{CNT} / \mathrm{mwGO}$ composite or CNT coated on a $43.20 \mathrm{~cm}^{3} \mathrm{RVC}$ electrode. It is observed from the figure that the CNT/RVC electrode when used in a CDI system required 103 desalination cycles for reducing solution concentration from $75 \mathrm{mg} / \mathrm{L}$ to $1 \mathrm{mg} / \mathrm{L}$. As each desalination cycle for this electrode takes 18 mins, hence, the total time required is 1854 mins (18 $\mathrm{min} \times 103$ cycles) for the production of $1 \mathrm{~L}$ of water that contains the $\mathrm{NaCl}$ concentration of less than $1 \mathrm{mg} / \mathrm{L}$. Thus, the desalinated water produced per day is $0.78 \mathrm{~L}$ using $1 \mathrm{~g}$ of CNT coated on a $43.20 \mathrm{~cm}^{3}$ RVC electrode, or $17,855 \mathrm{~L}$ using $1 \mathrm{~m}^{3}$ of the same composite electrode. On the other hand, by using the $9-\mathrm{CNT} / \mathrm{mwGO} / \mathrm{RVC}$ electrode in a CDI system, it is required 85 desalination cycles for the reduction of the same amount of solution concentration. This indicates that this electrode takes time for about $1105 \mathrm{mins}$ (13 $\mathrm{min} \times 85$ cycles) to produce $1 \mathrm{~L}$ desalinated water where it contains the same $\mathrm{NaCl}$ concentration. Thus, the water produced per day is $1.30 \mathrm{~L}$ using $1 \mathrm{~g}$ of $9-\mathrm{CNT} / \mathrm{mwGO}$ coated on a $43.20 \mathrm{~cm}^{3}$ RVC electrode or $29,958 \mathrm{~L}$ using $1 \mathrm{~m}^{3}$ of the same composite electrode. Hence, it can be inferred that the 9-CNT/mwGO/RVC composite electrode produced $67.78 \%$ more desalinated water per day compared to the CNT/RVC composite electrode when used in the same CDI system.

\section{Conclusions}

The CNT/mwGO composites at their different ratios were successfully coated on the RVC electrode to prepare 3D electrodes and used in the CDI cell. The results showed that the optimal electrode had very high CDI cyclic stability, maintaining an electrochemical cycling stability of $100 \%$ when measured up to five cycles. Moreover, the time saving of one electrosorption-desorption cycle with the 9$\mathrm{CNT} / \mathrm{mwGO} / \mathrm{RVC}$ electrode was $27.78 \%$, compared with the CNT/RVC electrode, which required $18 \mathrm{~min}$. In addition, the electrosorption removal of $\mathrm{NaCl}$ by the 9$\mathrm{CNT} / \mathrm{mwGO} / \mathrm{RVC}$ electrode in terms of mass of the electrode $(3.82 \mathrm{mg} / \mathrm{g})$ increased $18.27 \%$ compared to the CNT/RVC electrode $(3.23 \mathrm{mg} / \mathrm{g})$ when measured at the optimum condition. The optimum electrode, 9$\mathrm{CNT} / \mathrm{mwGO} / \mathrm{RVC}$ composite, showed a $67.78 \%$ increment per day in the desalinated water production compared to the CNT/RVC electrode at their same testing condition. The optimum electrode performed the highest $29,958 \mathrm{~L}$ production of water per day when using an electrode size of $1 \mathrm{~m}^{3}$. Moreover, the highest electrosorption capacity has resulted from the same electrode that is $10.84 \mathrm{mg} / \mathrm{g}$ at the solution feed concentration $500 \mathrm{mg} / \mathrm{L}$, whereas the theoretically calculated value through the Langmuir isotherm showed the maximum electrosorption capacity value of $16.59 \mathrm{mg} / \mathrm{g}$. The results for the 9-CNT/mwGO/RVC composite electrode demonstrate that it can be a promising electrode material in CDI technology.

\section{Data Availability}

The data can be found upon request to the corresponding author.

\section{Conflicts of Interest}

There is no competing financial interest among the authors.

\section{Acknowledgments}

The authors extend their appreciation to the Deanship of Scientific Research at King Saud University for funding this work through the research group (RG 1438-038).

\section{Supplementary Materials}

S1: the functionalization of CNTs. S2: synthesis of GO. S3: the exfoliation and reduction of GO using microwave irradiation. S4: the dispersion of mwGO and a-SWCNT. S5: preparation of the a-SWCNT/mwGO composite coating solution. S6: the pretreatment of the RVC electrode. S7: the optimization of RVC electrodes coated with a-SWCNT. S8: aSWCNT, mwGO, and a-SWCNT/mwGO composite dipcoated RVC electrodes. S9: the measurement and calculation of ion removal from the $\mathrm{NaCl}$ aqueous solution. S10: the construction of a capacitive deionization cell and desalination experiments. S11: the measurement of the effect of flow rate and voltage on the ion removal efficiency. S12: the calculation of the electrosorption capacity. S13: pseudofirst-order equation. S14: Langmuir and Freundlich isotherm. (Supplementary Materials)

\section{References}

[1] G. Wang, Q. Dong, Z. Ling, C. Pan, C. Yu, and J. Qiu, "Hierarchical activated carbon nanofiber webs with tuned structure fabricated by electrospinning for capacitive deionization," Journal of Materials Chemistry, vol. 22, no. 41, pp. 21819-21823, 2012.

[2] T. Wu, G. Wang, F. Zhan et al., "Surface-treated carbon electrodes with modified potential of zero charge for capacitive deionization," Water Research, vol. 93, pp. 30-37, 2016.

[3] Q. Dong, G. Wang, B. Qian, C. Hu, Y. Wang, and J. Qiu, "Electrospun composites made of reduced graphene oxide and activated carbon nanofibers for capacitive deionization," Electrochimica Acta, vol. 137, pp. 388-394, 2014.

[4] W. Xi and H. Li, "Vertically-aligned growth of CuAl-layered double oxides on reduced graphene oxide for hybrid capacitive deionization with superior performance," Environmental Science: Nano, vol. 7, no. 3, pp. 764-772, 2020. 
[5] C. Li, S. Wang, G. Wang et al., " $\mathrm{NH}_{4} \mathrm{~V}_{4} \mathrm{O}_{10} / \mathrm{rGO}$ composite as a high-performance electrode material for hybrid capacitive deionization," Environmental Science: Water Research \& Technology, vol. 6, no. 2, pp. 303-311, 2020.

[6] G. Wang, Q. Dong, T. Wu, F. Zhan, M. Zhou, and J. Qiu, "Ultrasound-assisted preparation of electrospun carbon fiber/graphene electrodes for capacitive deionization: importance and unique role of electrical conductivity," Carbon, vol. 103, pp. 311-317, 2016.

[7] S. Porada, R. Zhao, A. van der Wal, V. Presser, and P. M. Biesheuvel, "Review on the science and technology of water desalination by capacitive deionization," Progress in Materials Science, vol. 58, no. 8, pp. 1388-1442, 2013.

[8] A. Aldalbahi, M. Rahaman, and M. Almoiqli, "A strategy to enhance the electrode performance of novel threedimensional PEDOT/RVC composites by electrochemical deposition method," Polymers, vol. 9, no. 12, p. 157, 2017.

[9] A. Aldalbahi, M. Rahaman, P. Govindasami, M. Almoiqli, T. Altalhi, and A. Mezni, "Construction of a novel threedimensional PEDOT/RVC electrode structure for capacitive deionization: testing and performance," Materials, vol. 10, no. 7, p. 847, 2017.

[10] A. Aldalbahi, M. Rahaman, M. Almoigli, A. Meriey, and K. Alharbi, "Improvement in electrode performance of novel SWCNT loaded three-dimensional porous RVC composite electrodes by electrochemical deposition method," Nanomaterials, vol. 8, no. 1, p. 19, 2018.

[11] S. Iijima, "Helical microtubules of graphitic carbon," Nature, vol. 354, no. 6348, pp. 56-58, 1991.

[12] M. Meyyappan, Carbon Nanotubes: Science and Applications, CRC Press, Boca Raton, FL, USA, 2005.

[13] F. Li, H. M. Cheng, S. Bai, G. Su, and M. S. Dresselhaus, "Tensile strength of single-walled carbon nanotubes directly measured from their macroscopic ropes," Applied Physics Letters, vol. 77, no. 20, pp. 3161-3163, 2000.

[14] A. A. Balandin, "Thermal properties of graphene and nanostructured carbon materials," Nature Materials, vol. 10, no. 8, pp. 569-581, 2011.

[15] Y.-K. Kwon and P. Kim, "Unusually high thermal conductivity in carbon nanotubes," in High Thermal Conductivity Materials, S. Shindé and J. Goela, Eds., pp. 227-265, Springer, New York, NY, USA, 2006.

[16] S. Hong and S. Myung, "Nanotube electronics: a flexible approach to mobility," Nature Nanotechnology, vol. 2, no. 4, pp. 207-208, 2007.

[17] R. H. Baughman, A. A. Zakhidov, and W. A. de Heer, "Carbon nanotubes-the route toward applications," Science, vol. 297, no. 5582, pp. 787-792, 2002.

[18] H. Dai, J. H. Hafner, A. G. Rinzler, D. T. Colbert, and R. E. Smalley, "Nanotubes as nanoprobes in scanning probe microscopy," Nature, vol. 384, no. 6605, pp. 147150, 1996.

[19] E. Dervishi, Z. Li, Y. Xu et al., "Carbon nanotubes: synthesis, properties, and applications," Particulate Science and Technology, vol. 27, no. 2, pp. 107-125, 2009.

[20] M. S. Dresselhaus, G. Dresselhaus, and P. Avouris, Carbon Nanotubes: Synthesis, Structure, Properties, and Applications, Springer, London, UK, 2001.

[21] R. M. Reilly, "Carbon nanotubes: potential benefits and risks of nanotechnology in nuclear medicine," Journal of Nuclear Medicine, vol. 48, no. 7, pp. 1039-1042, 2007.
[22] L. P. Zanello, B. Zhao, H. Hu, and R. C. Haddon, "Bone cell proliferation on carbon nanotubes," Nano Letters, vol. 6, no. 3, pp. 562-567, 2006.

[23] D. Williams, "Carbon nanotubes in medical technology," Medical Device Technology, vol. 18, no. 2, pp. 8-10, 2007.

[24] S. J. Tans, A. R. M. Verschueren, and C. Dekker, "Room-temperature transistor based on a single carbon nanotube," Nature, vol. 393, no. 6680, pp. 49-52, 1998.

[25] C. Yan, L. Zou, and R. Short, "Single-walled carbon nanotubes and polyaniline composites for capacitive deionization," Desalination, vol. 290, pp. 125-129, 2012.

[26] S. Kar, R. C. Bindal, and P. K. Tewari, "Carbon nanotube membranes for desalination and water purification: challenges and opportunities," Nano Today, vol. 7, no. 5, pp. 385-389, 2012.

[27] L. Dumee, "Carbon-nanotube-based membranes for water desalination by membrane distillation," in Institute for Sustainability and Innovation, p. 370, Victoria University, 2011.

[28] K. I. Bolotin, K. J. Sikes, Z. Jiang et al., "Ultrahigh electron mobility in suspended graphene," Solid State Communications, vol. 146, no. 9-10, pp. 351-355, 2008.

[29] S. V. Morozov, K. S. Novoselov, M. I. Katsnelson et al., "Giant intrinsic carrier mobilities in graphene and its bilayer," Physical Review Letters, vol. 100, no. 1, 2008.

[30] C. Lee, X. Wei, J. W. Kysar, and J. Hone, "Measurement of the elastic properties and intrinsic strength of monolayer graphene," Science, vol. 321, no. 5887, pp. 385-388, 2008.

[31] A. A. Balandin, S. Ghosh, W. Bao et al., "Superior thermal conductivity of single-layer graphene," Nano Letters, vol. 8, no. 3, pp. 902-907, 2008.

[32] W. Cai, Y. Zhu, X. Li, R. D. Piner, and R. S. Ruoff, "Large area few-layer graphene/graphite films as transparent thin conducting electrodes," Applied Physics Letters, vol. 95, no. 12, p. 123115, 2009.

[33] X. Li, Y. Zhu, W. Cai et al., "Transfer of large-area graphene films for high-performance transparent conductive electrodes," Nano Letters, vol. 9, no. 12, pp. 4359-4363, 2009.

[34] Y. Xin, J. G. Liu, Y. Zhou et al., "Preparation and characterization of Pt supported on graphene with enhanced electrocatalytic activity in fuel cell," Journal of Power Sources, vol. 196, no. 3, pp. 1012-1018, 2011.

[35] Z. Wang, C. P. Puls, N. E. Staley et al., "Technology ready use of single layer graphene as a transparent electrode for hybrid photovoltaic devices," Physica E: Low-dimensional Systems and Nanostructures, vol. 44, no. 2, pp. 521-524, 2011.

[36] V. H. Luan, H. N. Tien, L. T. Hoa et al., "Synthesis of a highly conductive and large surface area graphene oxide hydrogel and its use in a supercapacitor," Journal of Materials Chemistry A, vol. 1, no. 2, pp. 208-211, 2013.

[37] E. W. Hill, A. Vijayaragahvan, and K. Novoselov, "Graphene sensors," IEEE Sensors Journal, vol. 11, no. 12, pp. 31613170, 2011.

[38] Y. Wu, K. A. Jenkins, A. Valdes-Garcia et al., "State-of-the-art graphene high-frequency electronics," Nano Letters, vol. 12, no. 6, pp. 3062-3067, 2012.

[39] B. C. Brodie, "On the atomic weight of graphite," Philosophical Transactions of the Royal Society of London, vol. 149, pp. 249259, 1859.

[40] L. Staudenmaier, "Verfahren zur darstellung der graphitsäure," Berichte der Deutschen Chemischen Gesellschaft, vol. 31, no. 2, pp. 1481-1487, 1898. 
[41] W. S. Hummers Jr. and R. E. Offeman, "Preparation of graphitic oxide," Journal of the American Chemical Society, vol. 80, no. 6, pp. 1339-1339, 1958.

[42] O. C. Compton and S. T. Nguyen, "Graphene oxide, highly reduced graphene oxide, and graphene: versatile building blocks for carbon-based materials," Small, vol. 6, no. 6, pp. 711-723, 2010.

[43] J. A. Johnson, C. J. Benmore, S. Stankovich, and R. S. Ruoff, "A neutron diffraction study of nano-crystalline graphite oxide," Carbon, vol. 47, no. 9, pp. 2239-2243, 2009.

[44] Z. Luo, Y. Lu, L. A. Somers, and A. T. C. Johnson, "High yield preparation of macroscopic graphene oxide membranes," Journal of the American Chemical Society, vol. 131, no. 3, pp. 898-899, 2009.

[45] D. C. Marcano, D. V. Kosynkin, J. M. Berlin et al., "Improved synthesis of graphene oxide," ACS Nano, vol. 4, no. 8, pp. 4806-4814, 2010.

[46] H. Hu, Z. Zhao, Q. Zhou, Y. Gogotsi, and J. Qiu, “The role of microwave absorption on formation of graphene from graphite oxide," Carbon, vol. 50, no. 9, pp. 3267-3273, 2012.

[47] H. Hu, Z. Zhao, W. Wan, Y. Gogotsi, and J. Qiu, "Ultralight and highly compressible graphene aerogels," Advanced Materials, vol. 25, no. 15, pp. 2219-2223, 2013.

[48] L. Wang, M. Wang, Z.-H. Huang et al., "Capacitive deionization of $\mathrm{NaCl}$ solutions using carbon nanotube sponge electrodes," Journal of Materials Chemistry, vol. 21, no. 45, pp. 18295-18299, 2011.

[49] K. S. Novoselov, A. K. Geim, S. V. Morozov et al., "Electric field effect in atomically thin carbon films," Science, vol. 306, no. 5696, pp. 666-669, 2004.

[50] K. P. Loh, Q. Bao, G. Eda, and M. Chhowalla, "Graphene oxide as a chemically tunable platform for optical applications," Nature Chemistry, vol. 2, no. 12, pp. 1015-1024, 2010.

[51] J. T. Robinson, F. K. Perkins, E. S. Snow, Z. Wei, and P. E. Sheehan, "Reduced graphene oxide molecular sensors," Nano Letters, vol. 8, no. 10, pp. 3137-3140, 2008.

[52] M. Zhou, Y. Zhai, and S. Dong, "Electrochemical sensing and biosensing platform based on chemically reduced graphene oxide," Analytical Chemistry, vol. 81, no. 14, pp. 5603-5613, 2009.

[53] G. Williams, B. Seger, and P. V. Kamat, "TiO 2 -graphene nanocomposites. UV-assisted photocatalytic reduction of graphene oxide," ACS Nano, vol. 2, no. 7, pp. 1487-1491, 2008.

[54] Y. Si and E. T. Samulski, "Synthesis of water soluble graphene," Nano Letters, vol. 8, no. 6, pp. 1679-1682, 2008.

[55] K. S. Kim, Y. Zhao, H. Jang et al., "Large-scale pattern growth of graphene films for stretchable transparent electrodes," Nature, vol. 457, no. 7230, pp. 706-710, 2009.

[56] H. Li, T. Lu, L. Pan, Y. Zhang, and Z. Sun, "Electrosorption behavior of graphene in $\mathrm{NaCl}$ solutions," Journal of Materials Chemistry, vol. 19, no. 37, pp. 6773-6779, 2009.

[57] H. Li, L. Pan, C. Nie, Y. Liu, and Z. Sun, "Reduced graphene oxide and activated carbon composites for capacitive deionization," Journal of Materials Chemistry, vol. 22, no. 31, pp. 15556-15561, 2012.

[58] H. Li, S. Liang, J. Li, and L. He, "The capacitive deionization behaviour of a carbon nanotube and reduced graphene oxide composite," Journal of Materials Chemistry A, vol. 1, no. 21, pp. 6335-6341, 2013.
[59] Y. Wimalasiri and L. Zou, "Carbon nanotube/graphene composite for enhanced capacitive deionization performance," Carbon, vol. 59, pp. 464-471, 2013.

[60] D. Antiohos, K. Pingmuang, M. S. Romano et al., "Manganosite-microwave exfoliated graphene oxide composites for asymmetric supercapacitor device applications," Electrochimica Acta, vol. 101, no. 4, pp. 99-108, 2013.

[61] A. Aldalbahi, M. Rahaman, M. Almoiqli, A. Hamedelniel, and A. Alrehaili, "Single-walled carbon nanotube (SWCNT) loaded porous reticulated vitreous carbon (RVC) electrodes used in a capacitive deionization (CDI) cell for effective desalination," Nanomaterials, vol. 8, no. 7, p. 527, 2018.

[62] A. Aldalbahi, M. Rahaman, and M. Almoiqli, "Performance enhancement of modified 3D SWCNT/RVC electrodes using microwave-irradiated graphene oxide," Nanoscale Research Letters, vol. 14, no. 1, p. 351, 2019.

[63] L. Pan, X. Wang, Y. Gao, Y. Zhang, Y. Chen, and Z. Sun, "Electrosorption of anions with carbon nanotube and nanofibre composite film electrodes," Desalination, vol. 244, no. 1-3, pp. 139-143, 2009.

[64] H. Li, L. Zou, L. Pan, and Z. Sun, "Using graphene nano-flakes as electrodes to remove ferric ions by capacitive deionization," Separation and Purification Technology, vol. 75, no. 1, pp. 814, 2010.

[65] H. Li, L. Pan, T. Lu, Y. Zhan, C. Nie, and Z. Sun, "A comparative study on electrosorptive behavior of carbon nanotubes and graphene for capacitive deionization," Journal of Electroanalytical Chemistry, vol. 653, no. 1-2, pp. 40-44, 2011.

[66] C. Valderrama, X. Gamisans, X. de las Heras, A. Farrán, and J. L. Cortina, "Sorption kinetics of polycyclic aromatic hydrocarbons removal using granular activated carbon: intraparticle diffusion coefficients," Journal of Hazardous Materials, vol. 157, no. 2-3, pp. 386-396, 2008.

[67] E. Demirbas, M. Kobya, E. Senturk, and T. Ozkan, “Adsorption kinetics for the removal of chromium (VI) from aqueous solutions on the activated carbons prepared from agricultural wastes," Water SA, vol. 30, no. 4, 2004.

[68] S. Lagergren, "About the theory of so-called adsorption of soluble substances," Svenska Vetens Kapsarsed Handle, vol. 24, no. 4, pp. 1-39, 1898.

[69] Z. Wang, B. Dou, L. Zheng, G. Zhang, Z. Liu, and Z. Hao, "Effective desalination by capacitive deionization with functional graphene nanocomposite as novel electrode material," Desalination, vol. 299, no. 4, pp. 96-102, 2012.

[70] H. Li, L. Zou, L. Pan, and Z. Sun, "Novel graphene-like electrodes for capacitive deionization," Environmental Science \& Technology, vol. 44, no. 22, pp. 8692-8697, 2010.

[71] H. Li, L. Pan, Y. Zhang et al., "Kinetics and thermodynamics study for electrosorption of $\mathrm{NaCl}$ onto carbon nanotubes and carbon nanofibers electrodes," Chemical Physics Letters, vol. 485, no. 1-3, pp. 161-166, 2010.

[72] S. Wang, D. Wang, L. Ji, Q. Gong, Y. Zhu, and J. Liang, "Equilibrium and kinetic studies on the removal of $\mathrm{NaCl}$ from aqueous solutions by electrosorption on carbon nanotube electrodes," Separation and Purification Technology, vol. 58, no. 1, pp. 12-16, 2007.

[73] H. Li and L. Zou, "Ion-exchange membrane capacitive deionization: a new strategy for brackish water desalination," Desalination, vol. 275, no. 1-3, pp. 62-66, 2011.

[74] C.-H. Hou, J.-F. Huang, H.-R. Lin, and B.-Y. Wang, "Preparation of activated carbon sheet electrode assisted 
electrosorption process," Journal of the Taiwan Institute of Chemical Engineers, vol. 43, no. 3, pp. 473-479, 2012.

[75] I. Villar, D. J. Suarez-De La Calle, Z. González et al., “Carbon materials as electrodes for electrosorption of $\mathrm{NaCl}$ in aqueous solutions," Adsorption, vol. 17, no. 3, pp. 467-471, 2011.

[76] P. W. Purdom, Environmental Health, Academic Press, New York, NY, USA, 2nd edition, 1980.

[77] V. Marichev, "Partial charge transfer during anion adsorptionMethodological aspects," Surface Science Reports, vol. 56, no. 8, pp. 277-324, 2005.

[78] I. Langmuir, "The adsorption of gases on plane surfaces of glass, mica and platinum," Journal of the American Chemical Society, vol. 40, no. 9, pp. 1361-1403, 1918.

[79] A. Kapoor, R. T. Yang, and C. Wong, "Surface diffusion," Catalysis Reviews, vol. 31, no. 1-2, pp. 129-214, 1989.

[80] Z. Chen, C. Song, X. Sun, H. Guo, and G. Zhu, "Kinetic and isotherm studies on the electrosorption of $\mathrm{NaCl}$ from aqueous solutions by activated carbon electrodes," Desalination, vol. 267, no. 2-3, pp. 239-243, 2011. 